\title{
El desarrollo de la Competencia Digital en el alumnado de Educación Infantil
}

\author{
The development of digital competence in Early Childhood Education
}

Ma del Mar Sánchez-Vera; mmarsanchez@um.es

Universidad de Murcia (España)

\section{Resumen}

La Competencia Digital no ha sido incluida, hasta ahora, en el currículo del segundo ciclo de Educación Infantil. No obstante, en los últimos años, diferentes estudios y experiencias educativas han puesto de relieve el potencial que tiene en esta etapa. Este artículo tiene como objetivo conocer y analizar qué aspectos de la Competencia Digital se pueden abordar, así como desarrollar una propuesta de indicadores de logro por edades. Para ello, primero se ha realizado un análisis curricular de la Competencia Digital, a continuación, se ha consultado a 18 maestras expertas en la integración de las tecnologías en el aula de 3 a 6 años.

Los resultados indican que son varios los elementos de la Competencia Digital que pueden integrarse en esta etapa, habiendo encontrado mayor acuerdo en los aspectos relacionados con el conocimiento de aplicaciones informáticas, desarrollo de la curiosidad por las TIC, pensamiento computacional, gestión de la información, usar recursos tecnológicos para resolver problemas y comunicarse. Los aspectos relacionados con la gestión y el uso de información de manera crítica se valoraron como los más complicados de trabajar en esta etapa, siendo elementos que se van incorporando de forma progresiva debido al propio desarrollo madurativo del alumnado.

Palabras clave: Competencia Digital, Educación Infantil, tecnología educativa, curriculum.

\section{Abstract}

Digital Competence has not been included, until now, in the curriculum of the second cycle of Early Childhood Education (Kindergarten). However, in recent years, different studies and educational innovations have highlighted the potential that it has. The aim of this article is to know and analyze which aspects of Digital Competence can be developed, as well as to develop a proposal of achievement indicators by age. For this purpose, first a curricular analysis of Digital Competence has been carried out, and then 18 teachers, who are experts in the integration of technologies in the classroom from 3 to 6 years, have been consulted.

The results show that there are several elements of Digital Competence that can be integrated at this stage, having found greater agreement in the aspects related to knowledge of computer applications, development of curiosity about ICT, computational thinking, information management, using technological resources to solve problems and communicate. Aspects related to the management and the use of information critically were considered the most complicated aspect to work on at this stage, being elements that are incorporated progressively due to the students' own maturity development.

Keywords: Digital Competence, Early Childhood Education, Educational Technology, computational, curriculum. 


\section{INTRODUCCIÓN. LA COMPETENCIA DIGITAL EN EL MUNDO EDUCATIVO}

En el año 2006 la Competencia Digital fue establecida como una de las siete competencias clave de los ciudadanos en este siglo por la Unión Europea, en su recomendación sobre las competencias clave para el aprendizaje permanente. Según la propia Comisión Europea, la Competencia Digital (EU, 2019, p.10) se referiría al:

"El uso confiado, crítico y responsable de las tecnologías digitales y la participación en ellas para el aprendizaje, el trabajo y la participación en la sociedad. Incluye la alfabetización informativa y de datos, la comunicación y la colaboración, la alfabetización mediática, la creación de contenidos digitales (incluida la programación), la seguridad (incluido el bienestar digital y las competencias relacionadas con la ciberseguridad), las cuestiones relacionadas con la propiedad intelectual, la resolución de problemas y el pensamiento crítico".

La Unión Europea ha establecido también el Marco Europeo de las Competencias Digitales para los ciudadanos, en lo que se ha denominado el modelo DigComp, que trata de especificar el conocimiento, habilidades y actitudes necesarias para utilizar las tecnologías en diferentes aspectos de la vida.

Desde inicios de este siglo han sido muchas las propuestas de definición y elementos de la Competencia Digital. El análisis realizado por Prendes, Gutiérrez y Martínez (2018) explica que las definiciones de Competencia Digital pueden categorizarse en dos perspectivas diferentes: por un lado, las que hacen hincapié en el enfoque técnico/tecnológico, y por otro lado, las que se centran en una perspectiva comunicativa.

Además de ello, a nivel conceptual, la Competencia Digital tiene vínculos con otros conceptos, como el de alfabetización digital. En este sentido. Zaho, Pinto y Sánchez (2021) indican que es un error sustituir conceptualmente un concepto por otro, ya que la Competencia Digital suele usarse para referirse a habilidades que hay que desarrollar, mientras que la alfabetización digital se refiere a la alfabetización a nivel técnico, informativo y mediático.

Cuando hablamos específicamente de Competencia Digital en el entorno educativo, el INTEF plantea tres tipos de Competencia Digital: la Competencia Digital del docente, la Competencia Digital de los centros educativos y la Competencia Digital del alumnado. En este artículo nos centraremos en la Competencia Digital del alumnado. Desde la publicación de la LOE (2006), la Competencia Digital ha sido incorporada como una de las competencias básicas a nivel educativo.

La Competencia Digital es, por tanto, definida como competencia clave e implica "el uso creativo, crítico y seguro de las tecnologías de la información y la comunicación para alcanzar los objetivos relacionados con el trabajo, la empleabilidad, el aprendizaje, el uso del tiempo libre, la inclusión y participación en la sociedad" (Orden ECD/65/2015). 
Figura 1. Elementos de la Competencia Digital propuestos en la LOMCE (2013). Ministerio de Educación y Formación profesional.

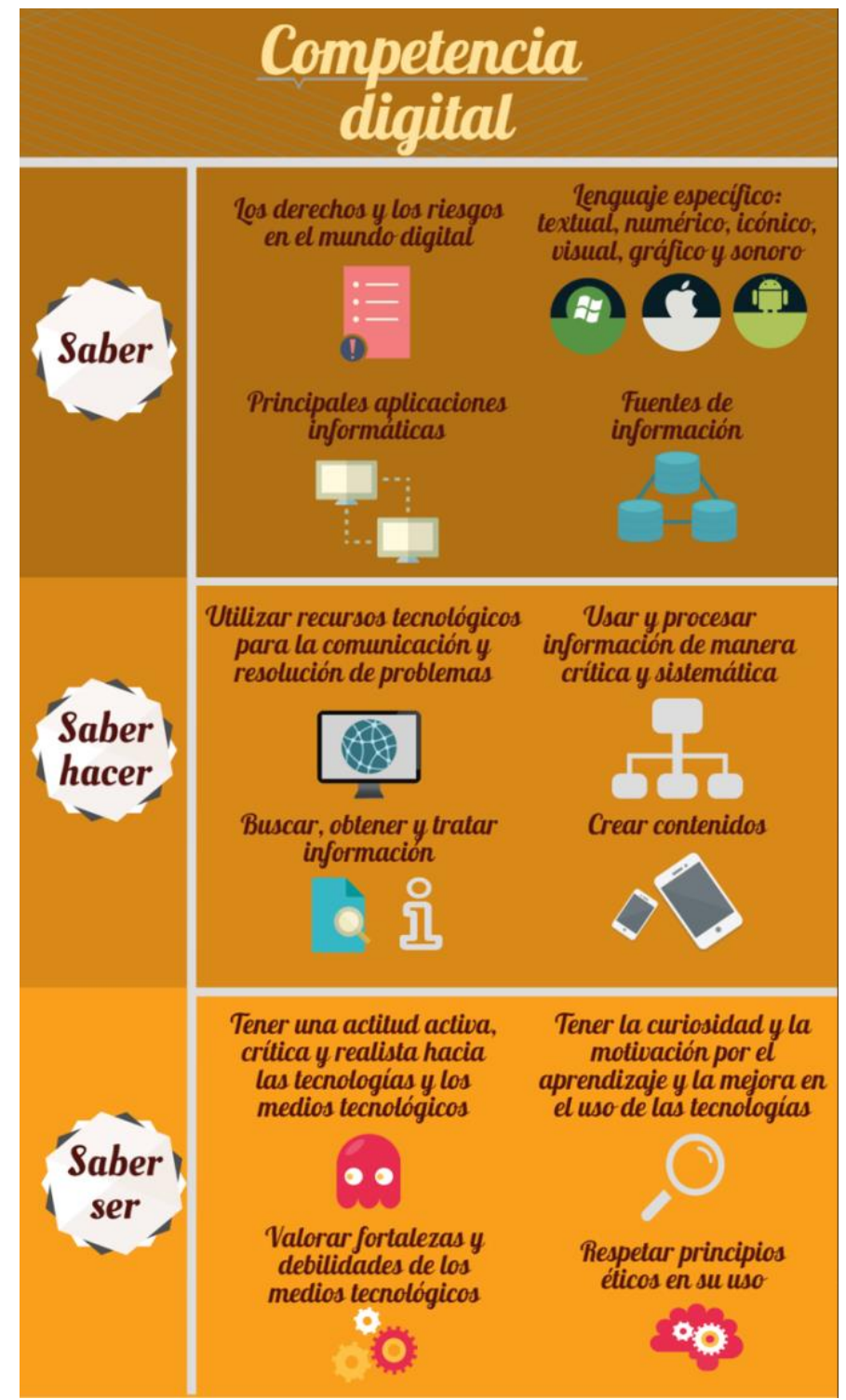

Este artículo se centra en la Educación Infantil, no obstante, el curriculum actual no contempla el desarrollo de la Competencia Digital en esta etapa, siendo la Educación Primaria la primera etapa en la que se menciona de manera curricular la Competencia Digital. Por tanto, se ha considerado relevante realizar una búsqueda en el Real Decreto 126/2018 de currículo básico de Educación Primaria de contenidos, criterios de evaluación y estándares de aprendizaje que podrían contribuir al desarrollo de la Competencia Digital del alumnado, para ver de qué manera se contempla a nivel curricular y fundamentar el posterior análisis para Educación Infantil. Para ello, se han utilizado términos de búsqueda como: digital, tecnología, TIC, seguridad y derechos (relacionados con el mundo digital), comunicación/comunicarse (relacionados con entornos en red). Los resultados pueden observarse en la Tabla 1 
Tabla 1. relación de contenidos, criterios de evaluación y estándares de aprendizaje del Real Decreto 126/2018 de currículo básico de Educación Primaria que contribuirían al desarrollo de la Competencia Digital del alumnado.

\begin{tabular}{|c|c|c|c|}
\hline Área & Contenido & Criterios de evaluación & Estándares de aprendizaje evaluables \\
\hline $\begin{array}{l}\text { Lengua } \\
\text { Castellana y } \\
\text { Literatura }\end{array}$ & & $\begin{array}{l}\text { Utilizar programas } \\
\text { educativos digitales para } \\
\text { realizar tareas y avanzar en } \\
\text { el aprendizaje. } \\
\text { Utilizar las TIC de modo } \\
\text { eficiente y responsable para } \\
\text { presentar sus producciones. } \\
\text { Utilizar las TIC de modo } \\
\text { eficiente y responsable para } \\
\text { la búsqueda y tratamiento } \\
\text { de la información. }\end{array}$ & $\begin{array}{l}\text { Usa con eficacia las nuevas } \\
\text { tecnologías para escribir, presentar } \\
\text { los textos y buscar información. } \\
\text { Utiliza Internet y las TIC: reproductor } \\
\text { de vídeo, reproductor de DVD, } \\
\text { ordenador, reproductor de CD-audio, } \\
\text { cámara de fotos digital y grabadora } \\
\text { de audio como recursos para la } \\
\text { realización de tareas diversas: escribir } \\
\text { y modificar un texto, crear tablas y } \\
\text { gráficas, etc. }\end{array}$ \\
\hline $\begin{array}{l}\text { Ciencias de la } \\
\text { Naturaleza }\end{array}$ & $\begin{array}{l}\text { Utilización de las } \\
\text { tecnologías de la } \\
\text { información } \\
\text { comunicación para } \\
\text { buscar y seleccionar } \\
\text { información, simular } \\
\text { procesos y presentar } \\
\text { conclusiones. } \\
\text { Beneficios y riesgos de } \\
\text { las tecnologías y } \\
\text { productos. } \\
\text { Búsqueda guiada de } \\
\text { información en la red. } \\
\text { Control del tiempo y } \\
\text { uso responsable de las } \\
\text { tecnologías de la } \\
\text { información y la } \\
\text { comunicación. }\end{array}$ & & $\begin{array}{l}\text { Hace un uso adecuado de las } \\
\text { tecnologías de la información y la } \\
\text { comunicación como recurso de ocio } \\
\text { Conoce y utiliza las medidas de } \\
\text { protección y seguridad personal que } \\
\text { debe utilizar en el uso de las } \\
\text { tecnologías de la información y la } \\
\text { comunicación. } \\
\text { Conoce y explica algunos de los } \\
\text { avances de la ciencia en: el hogar y la } \\
\text { vida cotidiana, la medicina, la cultura } \\
\text { y el ocio, el arte, la música, el cine y el } \\
\text { deporte y las tecnologías de la } \\
\text { información y la comunicación. } \\
\text { Utiliza algunos recursos a su alcance } \\
\text { proporcionados por las tecnologías } \\
\text { de la información para comunicarse y } \\
\text { colaborar }\end{array}$ \\
\hline $\begin{array}{l}\text { Ciencias } \\
\text { Sociales }\end{array}$ & $\begin{array}{lrr}\text { Utilización de } & \text { las } \\
\text { tecnologías de } & \text { la } \\
\text { información y } & \text { la } \\
\text { comunicación } & \text { para } \\
\text { buscar y seleccionar } \\
\text { información } & \text { y } \\
\text { presentar } & & \\
\text { conclusiones. } & \end{array}$ & $\begin{array}{l}\text { Utilizar las tecnologías de la } \\
\text { información y la } \\
\text { comunicación para obtener } \\
\text { información aprender y } \\
\text { expresar contenidos sobre } \\
\text { Ciencias Sociales }\end{array}$ & $\begin{array}{l}\text { Utiliza la tecnologías de la } \\
\text { información y la comunicación } \\
\text { (Internet, blogs, redes sociales) para } \\
\text { elaborar trabajos con la terminología } \\
\text { adecuada a los temas tratados. } \\
\text { Analiza informaciones relacionadas } \\
\text { con el área y maneja imágenes, } \\
\text { tablas, gráficos, esquemas, }\end{array}$ \\
\hline
\end{tabular}




\begin{tabular}{|c|c|c|c|}
\hline Área & Contenido & Criterios de evaluación & Estándares de aprendizaje evaluables \\
\hline & & & $\begin{array}{l}\text { resúmenes y las tecnologías de la } \\
\text { información y la comunicación }\end{array}$ \\
\hline Matemáticas & $\begin{array}{lcr}\text { Integración de } & \text { las } \\
\text { tecnologías de } & \text { la } \\
\text { información y y } & \text { la } \\
\text { comunicación en } & \text { el } \\
\text { proceso } & & \text { de } \\
\text { aprendizaje. } & & \\
\end{array}$ & & $\begin{array}{l}\text { Realiza un proyecto, elabora y } \\
\text { presenta un informe creando } \\
\text { documentos digitales propios (texto, } \\
\text { presentación, imagen, video, sonido), } \\
\text { buscando, analizando y } \\
\text { seleccionando la información } \\
\text { relevante, utilizando la herramienta } \\
\text { tecnológica adecuada y } \\
\text { compartiéndolo con sus compañeros. }\end{array}$ \\
\hline $\begin{array}{l}\text { Primera } \\
\text { lengua } \\
\text { extranjera }\end{array}$ & $\begin{array}{l}\text { Léxico ora, léxico } \\
\text { escrito, de alta } \\
\text { frecuencia relativo a } \\
\text { [...] tecnologías de la } \\
\text { información y la } \\
\text { comunicación }\end{array}$ & & \\
\hline $\begin{array}{l}\text { Educación } \\
\text { artística }\end{array}$ & & 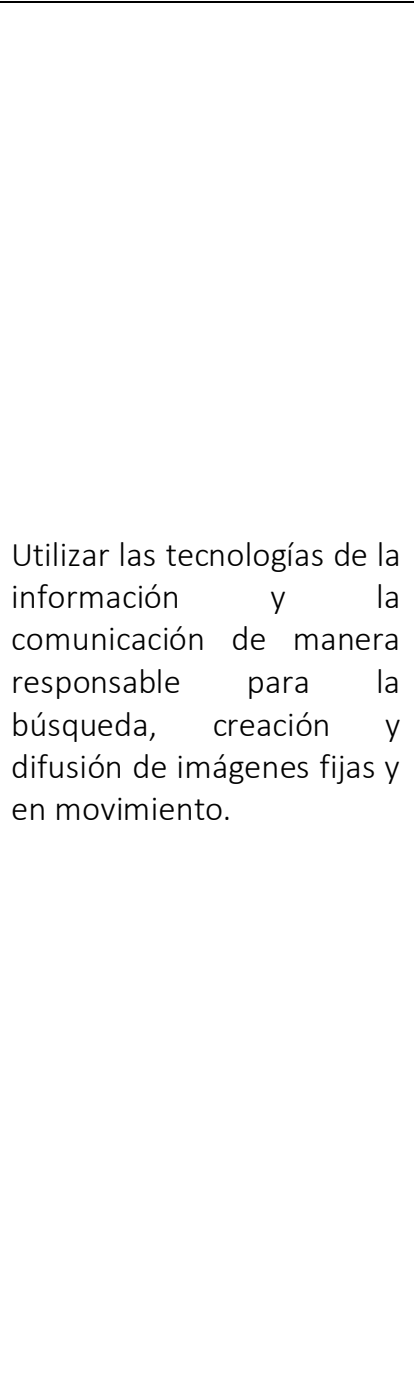 & $\begin{array}{l}\text { Conoce la evolución de la fotografía } \\
\text { del blanco y negro al color, de la } \\
\text { fotografía en papel a la digital, y } \\
\text { valora las posibilidades que ha } \\
\text { proporcionado la tecnología. } \\
\text { Maneja programas informáticos } \\
\text { sencillos de elaboración y retoque de } \\
\text { imágenes digitales (copiar, cortar, } \\
\text { pegar, modificar tamaño, color, brillo, } \\
\text { contraste...) que le sirvan para la } \\
\text { ilustración de trabajos con textos. } \\
\text { Conoce las consecuencias de la } \\
\text { difusión de imágenes sin el } \\
\text { consentimiento de las personas } \\
\text { afectadas y respeta las decisiones de } \\
\text { las mismas. } \\
\text { Realiza fotografías, utilizando medios } \\
\text { tecnológicos, analizando } \\
\text { posteriormente si el encuadre es el } \\
\text { más adecuado al propósito inicial. } \\
\text { Organiza y planea su propio proceso } \\
\text { creativo partiendo de la idea, } \\
\text { recogiendo información bibliográfica, } \\
\text { y eligiendo los que mejor se adecúan } \\
\text { a sus propósitos en la obra final, sin } \\
\text { utilizar elementos estereotipados, } \\
\text { siendo capaz de compartir con otros }\end{array}$ \\
\hline
\end{tabular}




\begin{tabular}{|c|c|c|c|}
\hline Área & Contenido & Criterios de evaluación & Estándares de aprendizaje evaluables \\
\hline & & & $\begin{array}{l}\text { alumnos el proceso y el producto final } \\
\text { obtenido }\end{array}$ \\
\hline $\begin{array}{l}\text { Educación } \\
\text { Física }\end{array}$ & & 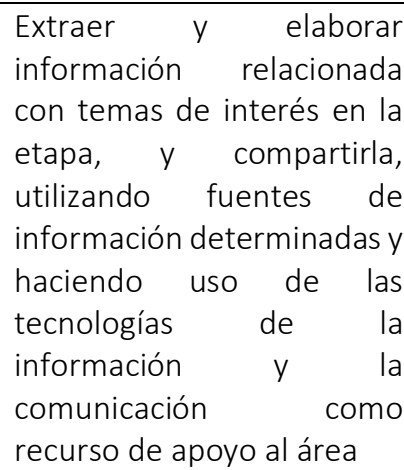 & $\begin{array}{l}\text { Utiliza las nuevas tecnologías para } \\
\text { localizar y extraer la información que } \\
\text { se le solicita. }\end{array}$ \\
\hline $\begin{array}{l}\text { Valores } \\
\text { sociales } \\
\text { cívicos }\end{array}$ & & $\begin{array}{l}\text { Emplear las nuevas } \\
\text { tecnologías desarrollando } \\
\text { valores sociales y cívicos en } \\
\text { entornos seguros }\end{array}$ & $\begin{array}{l}\text { Realiza un uso ético de las nuevas } \\
\text { tecnologías. } \\
\text { Conoce el empleo seguro de las } \\
\text { nuevas tecnologías. } \\
\text { Analiza y enjuicia críticamente los } \\
\text { contenidos del entorno digital. } \\
\text { Investiga sobre las principales causas } \\
\text { de los accidentes de tráfico con la } \\
\text { ayuda de las nuevas tecnología }\end{array}$ \\
\hline
\end{tabular}

La reforma del sistema educativo presentada en 2020, la LOMLOE, también incluye la Competencia Digital como un eje fundamental, destacando la capacitación para garantizar la plena inserción del alumnado en la sociedad digital como uno de los fines del sistema educativo español (artículo 2, LOMLOE, 2020).

La ley se encuentra en proceso de concreción curricular de las enseñanzas mínimas para cada etapa, pero en la publicación de la legislación general, se insiste en la necesidad de tener en cuenta el cambio digital que se está produciendo en nuestras sociedades y que forzosamente afecta a la comunidad educativa. Específicamente indica que "con el objetivo de que el sistema educativo adopte el lugar que le corresponde en el cambio digital, se incluye la atención al desarrollo de la Competencia Digital de los y las estudiantes de todas las etapas educativas, tanto a través de contenidos específicos como en una perspectiva transversal, y haciendo hincapié en la brecha digital de género" (LOMLOE, 2020, p.4). La ley indica que de 10 a 3ㅇ de la ESO se deberá incluir una materia optativa para el desarrollo de la Competencia Digital. 


\section{LA COMPETENCIA DIGITAL EN LA EDUCACIÓN INFANTIL}

La Competencia Digital, teniendo en cuenta los decretos de desarrollo de enseñanzas mínimas para esta etapa que están publicados hasta la fecha, no ha sido incluida en Educación Infantil. No obstante, el Real Decreto 1630/2006, de 29 de diciembre establecía la importancia de realizar una primera aproximación en el uso de las TIC y al uso apropiado del lenguaje audiovisual.

Se ha realizado una búsqueda en Real Decreto 1630/2006 de currículo básico de Educación Infantil, de elementos que aparecen en las áreas establecidas para esta etapa y que podrían contribuir al desarrollo de la Competencia Digital. Para ello, se han utilizado los mismos términos que se utilizaron previamente en Educación Primaria. Los resultados pueden observarse en la Tabla 2.

Tabla 2. relación de contenidos del Real Decreto 1630/2006 de currículo básico de la Educación Infantil que contribuirían al desarrollo de la Competencia Digital del alumnado. Elaboración propia

\begin{tabular}{|c|c|c|}
\hline $\begin{array}{l}\text { Área Lenguajes: } \\
\text { comunicación y } \\
\text { representación }\end{array}$ & $\begin{array}{l}\text { Las diferentes formas de comunicación y } \\
\text { representación que se integran en esta área } \\
\text { son: El Lenguaje verbal, el lenguaje artístico, el } \\
\text { lenguaje corporal, el lenguaje audiovisual y de } \\
\text { las tecnologías de la información y la } \\
\text { comunicación. } \\
\text { El lenguaje audiovisual y las tecnologías de la } \\
\text { información y la comunicación presentes en la } \\
\text { vida infantil, requieren un tratamiento } \\
\text { educativo que, a partir del uso apropiado, inicie } \\
\text { a niñas y niños en la comprensión de los } \\
\text { mensajes audiovisuales y en su utilización } \\
\text { adecuada. }\end{array}$ & $\begin{array}{l}\text { Bloque 2. Lenguaje audiovisual y } \\
\text { tecnologías de la información y la } \\
\text { comunicación. } \\
\text { Iniciación en el uso de } \\
\text { instrumentos tecnológicos como } \\
\text { ordenador, cámara o } \\
\text { reproductores de sonido e imagen, } \\
\text { como elementos de comunicación. } \\
\text { Acercamiento a producciones } \\
\text { audiovisuales como películas, } \\
\text { dibujos animados o videojuegos. } \\
\text { Valoración crítica de sus } \\
\text { contenidos y de su estética. } \\
\text { Distinción progresiva entre la } \\
\text { realidad y la representación } \\
\text { audiovisual. } \\
\text { Toma progresiva de conciencia de } \\
\text { la necesidad de un uso moderado } \\
\text { de los medios audiovisuales y de } \\
\text { las tecnologías de la información y } \\
\text { la comunicación. }\end{array}$ \\
\hline $\begin{array}{l}\text { Conocimiento del } \\
\text { entorno }\end{array}$ & $\begin{array}{l}\text { La importancia de las tecnologías como parte de } \\
\text { los elementos del entorno aconsejan que niñas } \\
\text { y niños identifiquen el papel que estas } \\
\text { tecnologías tienen en sus vidas, interesándose } \\
\text { por su conocimiento e iniciándose en su uso. }\end{array}$ & \\
\hline
\end{tabular}


Esta propuesta curricular es del año 2006. Desde entonces se han desarrollado diferentes estudios y experiencias educativas que han puesto de relieve el potencial que podría tener el desarrollo de la Competencia Digital en esta etapa (Sevillano y Rodríguez, 2013; Recio, 2015; Gómez-Galán, López-Meneses y Molina García, 2016; Romero, Gutiérrez-Castillo y Puig, 2017). Las actas del I Congreso Internacional de Innovación y Tecnología Educativa en Educación Infantil de 2016 ponen en evidencia algunos de los temas de interés relacionados con esta etapa. Por un lado, tenemos herramientas como la PDI, la realidad aumentada y la robótica, que pueden ser utilizadas en esta etapa, por otro lado, tenemos estrategias educativas como la gamificación, el aprendizaje basado por proyectos, el uso de webquest, y otras estrategias de aprendizaje activo.

Los estudios sobre la eficacia de la integración de las tecnologías en Educación Infantil son escasos, aunque Ramírez et al (2021) encuentran en su revisión que las conclusiones de algunos apuntan a una mejora de la lecto-escritura y de otras competencias clave, como las matemáticas y la autonomía personal. En general, Sevillano y Rodríguez (2013) indican que las maestras de esta etapa hacen una valoración positiva del uso de las TIC en el aula de infantil, destacando que a veces son ellas mismas las que aportan recursos tecnológicos propios en actividades con el alumnado.

Existen algunas experiencias europeas en torno a la integración de manera oficial de la Competencia Digital en esta etapa. Hardesen y Björk (2012) recogen información sobre un estudio llevado a cabo por el gobierno noruego en más de 1000 familias para conocer qué tipo de Competencia Digital poseían los niños y niñas de 0 a 6 años. El estudio concluye que éstos tienen amplias y diversas estrategias con dispositivos digitales. Encontraron que, en general, hasta los 6 años, tienen contacto con televisión, consolas de juego, ordenadores, cámaras digitales, teléfonos móviles y tabletas. Aunque hay diferencias por edades (por ejemplo, los más pequeños usan más dispositivos como la televisión), la tableta es la más común en todos los grupos de edad. Concluye este estudio que han de planificarse actividades tanto dirigidas como libres que incorporen la tecnología a nivel pedagógico de 0 a 6 años, ya que es importante, no solo para construir conocimiento y ayudar al alumnado a enfrentarse al mundo digital, sino también para la participación como miembro crítico y democrático de la sociedad.

Ramírez et al (2021) proponen un instrumento para evaluar las habilidades digitales del alumnado de infantil de 3 a 6 años de edad. En su estudio encuentran que la mayoría de los alumnos de infantil son capaces de usar con autonomía diferentes herramientas digitales cuando terminan el 2o ciclo, como el manejo del ratón, encender y apagar equipos, utilización de programas de edición, comprender objetivos de los juegos digitales, etc.

En cuanto a la robótica y la programación en Educación Infantil, Martínez y Gómez (2018) indican en su estudio, realizado a partir de trabajos con grupos focales, que los alumnos/as de 5 años son capaces de establecer correspondencia entre el código que programan y el desplazamiento del robot, por lo que pueden desarrollar el concepto de ordenador como una tecnología que los humanos programamos. Esto les sirvió para entender que otras tecnologías cotidianas, como una lavadora o incluso un determinado juguete, funcionan como objetos programables. 
Finalmente, recogemos un estudio para la Comisión Europea, llevado a cabo por Chaudron, Di Gioia y Gemo (2018), que recoge información de 17 países explorando cómo los niños de 0 a 8 años interactúan con las tecnologías. Entre sus conclusiones encontramos que el desarrollo de las habilidades digitales se da principalmente en el hogar. Los niños aprenden observando y ejecutando el comportamiento de los adultos y niños mayores cercanos. También indica que los niños y niñas de esas edades son más conscientes de los riesgos de las tecnologías si la escuelas las integra de forma significativa a nivel educativo. En su análisis sobre la situación en España, indican algunos aspectos de interés (Chaudron, Di Gioia y Gemo, 2018, p.175):

- Hay una mayor integración de las tecnologías en los hogares que en las escuelas, dónde su implementación ha sido más lenta.

- La mayoría de los hogares están equipados con múltiples dispositivos digitales. Su uso principal es para el ocio (jugar, ver videos...).

- Las familias consideran que la interacción de los niños con las tecnologías es inevitable y que aumentará conforme crezcan, y que será una parte importante de su futura vida laboral. También muestran preocupación en relación a los riesgos.

- Incluso en familias de bajo poder adquisitivo, se otorga importancia a tener y disponer de tecnología. Las familias más favorecidas socioeconómicamente tienden a ser más restrictivas con el tiempo de exposición a la tecnología.

- Los niños utilizan la tecnología para cultivar sus pasiones. La preferencia a determinadas actividades, como bailar o cocinar, determina lo que los niños hacen con los dispositivos.

Resulta interesante observar como, al mismo tiempo que se revindica la importancia de integrar las tecnologías en el aula, surgen tendencias educativas, específicamente en Educación Infantil, que se autodefinen como alternativas. Como indican Sánchez y Solano (2016) bajo la denominación "escuela libre" se aglutina todo tipo de perspectivas educativas, por lo que es complicado clasificarlas adecuadamente. No obstante, en este conglomerado de tipología, algunas noticias ${ }^{1}$ parecen hacer entrever algunas corrientes anti-tecnología en el aula. En este sentido, tenemos que recuperar los principios de la Tecnología Educativa para destacar que: el aprendizaje no se encuentra en función del medio, los recursos digitales no son ni buenos ni malos, siendo el docente el elemento más significativo en su adecuada integración (Cabero, 2003). También resulta importante destacar que los niños y niñas no viven aislados en un mundo sin tecnología, y es un derecho recibir la educación básica que le permita desarrollarse de manera adecuada en la sociedad. El desarrollo de la sociedad de la información es rápido y la escuela necesita incorporar habilidades no solo técnicas en relación al uso de las tecnologías, sino también en cuanto a cómo utilizarlas adecuadamente.

${ }^{1}$ https://elpais.com/sociedad/2019/03/20/actualidad/1553105010 527764.html 


\section{MÉTODO}

La finalidad de este estudio ha sido la de conocer y analizar qué aspectos de la Competencia Digital se pueden abordar en el segundo ciclo de la etapa de Educación Infantil, así como desarrollar una propuesta de indicadores de logro para cada curso de esta etapa.

Como afirma Reeves (2000), la investigación en Tecnología Educativa requiere de que la teoría del aprendizaje se crea en colaboración con los investigadores y los profesionales de la enseñanza, entre ellos, los docentes. Por ello, para poder conseguir el objetivo indicado, se ha planteado la necesidad de contar con profesorado de la etapa de Educación Infantil, para que a partir de su experiencia práctica identificaran qué elementos de la Competencia Digital se pueden desarrollar en Educación Infantil.

Se ha contado con maestras de Educación Infantil de 2ํㅜ ciclo que son expertas en la integración de las TIC en Educación Infantil. Se ha realizado, por tanto, un muestreo no probabilístico de tipo intencional. Como afirman (McMillan y Schumacher, 2005, p.142) "en investigación sobre enseñanza eficaz, puede resultar más revelador entrevistar al personal adecuado que a una muestra aleatoria de toda la plantilla".

De este modo se ha consultado a maestras que tuvieran más de 5 años como docentes de Educación Infantil y con experiencia integrando las TIC en el aula. También se ha tenido en cuenta su experiencia en la integración tecnologías emergentes, como el pensamiento computacional y la robótica en el aula de infantil.

La muestra está formada en total por 18 maestras de Educación Infantil. El 22,2\% de ellas tienen de 1 a 10 años de experiencia docente, el 38,9\% tiene entre 10 y 20 años de experiencia, el $16,7 \%$ tiene entre 20 y 30 años de experiencia, y el 22,2\% tiene más de 30 años de experiencia docente. Del total de maestras, la mitad (50\%) tiene entre 1 y 10 años de experiencia integrando las tecnologías como docente en el aula de infantil, el 38,9\% tiene entre 10 y 20 años, y el $11,1 \%$ tiene entre 20 y 30 años de experiencia.

La valoración y opinión de las docentes fue recogida a través de un cuestionario, validado mediante juicio de expertos, y compuesto de preguntas cerradas y abiertas. En el cuestionario se incluyen dos preguntas con ítems que se valoran con una escala tipo Likert para valorar el nivel de acuerdo o desacuerdo con los diferentes componentes de la Competencia Digital, extraídos de la propuesta del Ministerio de Educación ${ }^{2}$ (Figura 1). También se incluyen tres preguntas abiertas en las que se solicita que las maestras, desde su experiencia en la integración de las tecnologías en el aula, indiquen el nivel de logro respecto a la Competencia Digital diferenciándolo para 3, 4 y 5 años.

\footnotetext{
${ }^{2}$ http://www.educacionyfp.gob.es/educacion/mc/lomce/curriculo/competencias-clave/digital.html 


\section{RESULTADOS}

En cuanto a los elementos de la Competencia Digital, se consultó a las maestras cuáles consideran que el alumnado puede desarrollar durante la etapa de Educación Infantil y en qué medida. Los resultados pueden observarse en el Gráfico 1.

Indica qué elementos de la competencia digital se pueden desarrollar en la etapa de Educación Infantil y en qué medida

Desarrollo del pensamiento computacional

Protegerse y desarrollar conductas seguras en red Respetar principios éticos de uso

Valorar fortalezas y debilidades de los medios. Curiosidad y motivación por el aprendizaje a través..

Tener una actitud crítica hacia las tecnologías Crear contenidos digitales

Usar y procesar información de forma crítica

Buscar, obtener y tratar información

Usar recursos tecnológicos para resolver problemas

Usar recursos tecnológicos para comunicarse

Conocer algunas aplicaciones informáticas

Conocer los derechos y riesgos en un mundo digital
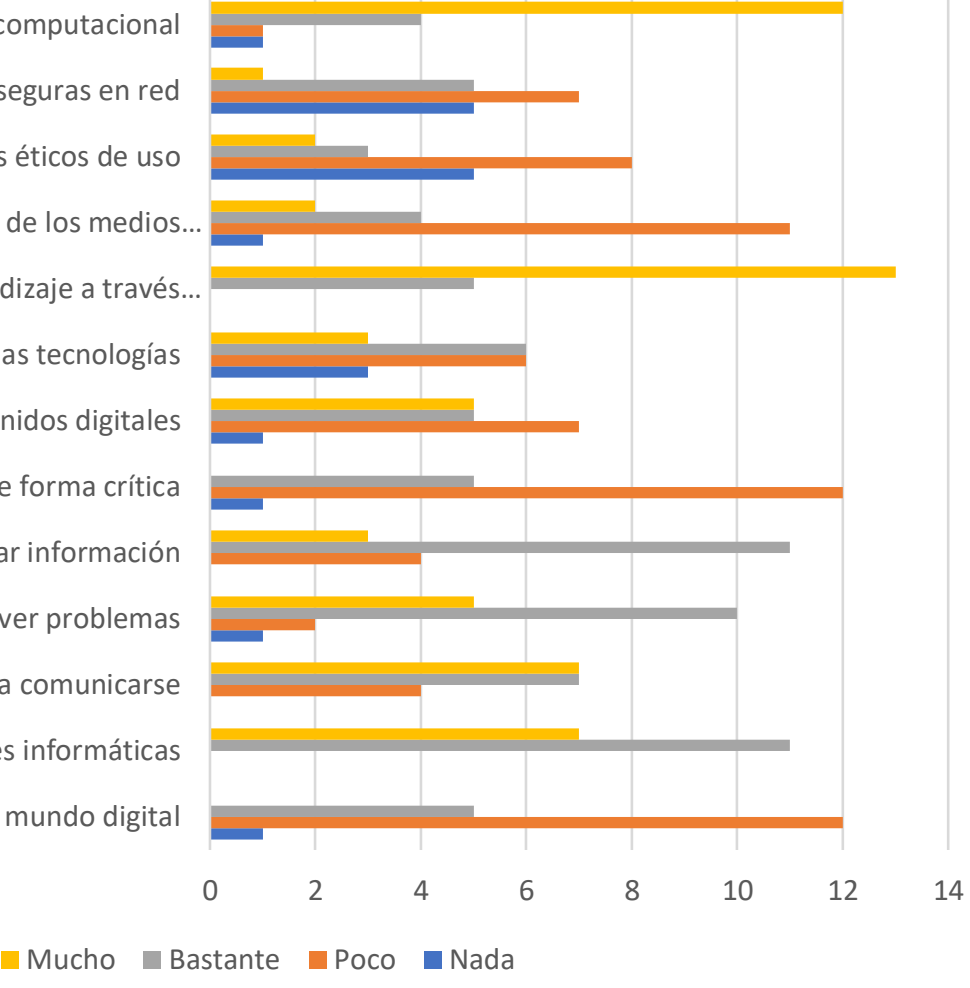

Figura 2. Elementos de la Competencia Digital que se pueden desarrollar en la etapa de Educación Infantil

Como se puede observar, hay una serie de ítems que han sido valorados por las maestras como elementos que pueden ser bastante o muy trabajados en la etapa de Educación Infantil (señalados al menos por 14 de las 18 maestras). Y son:

- Conocer algunas aplicaciones informáticas.

- Tener curiosidad y motivación por el aprendizaje a través de las tecnologías.

- Desarrollar el pensamiento computacional.

- Usar recursos tecnológicos para resolver problemas.

- Usar recursos tecnológicos para comunicarse.

- Buscar, obtener y tratar información.

Los elementos que han sido menos valorados para esta etapa (señalados así al menos por 14 de las 18 maestras) son:

- Conocer los derechos y riesgos en un mundo digital. 
- Usar y procesar información de manera crítica.

A continuación, se indicó que establecieran su grado de acuerdo/desacuerdo con algunas afirmaciones relacionadas con la Competencia Digital y la integración de las tecnologías en el aula de Educación Infantil.

El 94,4\% de las maestras indican que la Competencia Digital puede empezar a desarrollarse durante la Educación Infantil, estando el 77\% totalmente de acuerdo con esta afirmación. El $94,4 \%$ está de acuerdo con la afirmación que indica que el uso de recursos digitales no sustituye el uso de otros recursos en el aula de Infantil. El 83\% de las maestras indican que para trabajar las tecnologías es necesario dedicar un espacio y tiempo específico a las mismas, mientras que el $16,6 \%$ se muestra en desacuerdo a este aspecto.

En relación a cómo integrar la competencia digital, el 88\% indica que para integrarla en el aula de Educación Infantil, sería mejor utilizar un enfoque transversal. Todas las maestras consideran que es adecuado integrar las TIC en el aula de infantil. El 77,7\% de las maestras indican que se necesita más formación técnica para que el profesorado sepa cómo integrar las TIC en el aula de Infantil. El 94,4\% indica que se necesita más formación pedagógica.

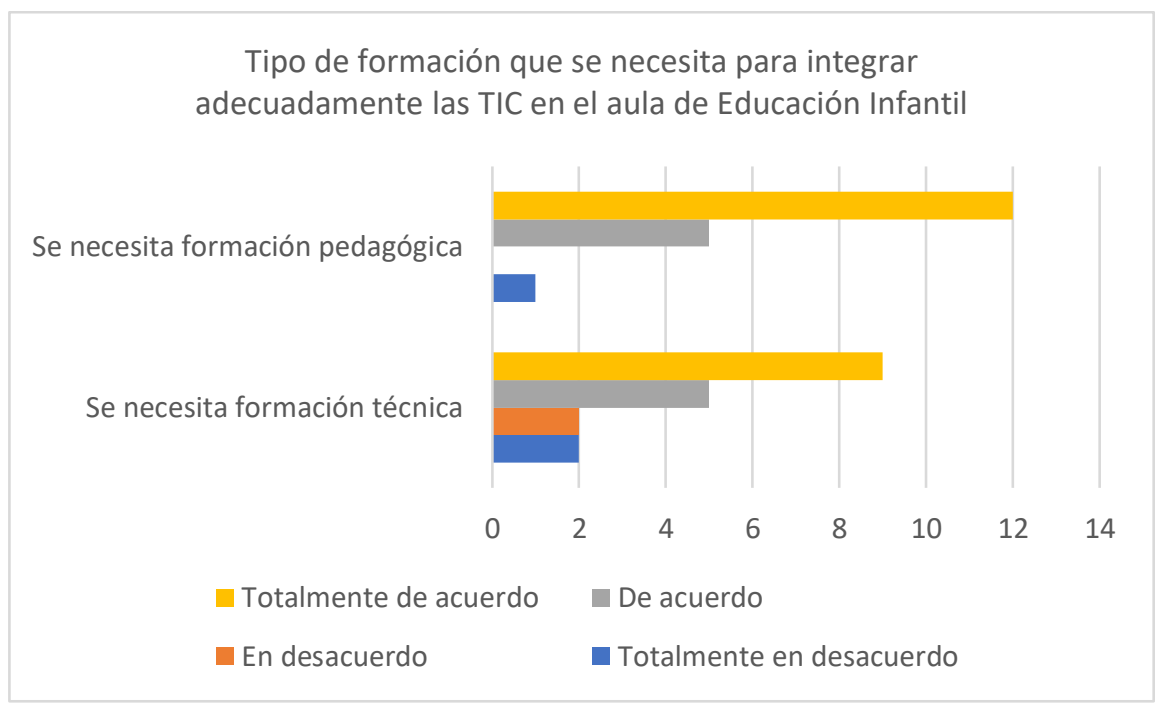

Figura 3. Tipo de formación que necesita el profesorado para integra las TIC en el aula de Educación Infantil

Finalmente, en el cuestionario se incluían tres preguntas abiertas, con la idea de que las maestras, a partir de su propia experiencia en el aula, expusieran distintos indicadores de logro que pueden adquirir los niños/as de Educación Infantil de segundo ciclo en cada curso académico. En la Tabla 1 se han recogido y organizado los resultados:

Tabla 1. Indicadores de logro relacionados con la Competencia Digital para cada curso del 2o ciclo de Educación Infantil, propuestos por maestras en ejercicio con experiencia en la integración de las tecnologías en el aula. 


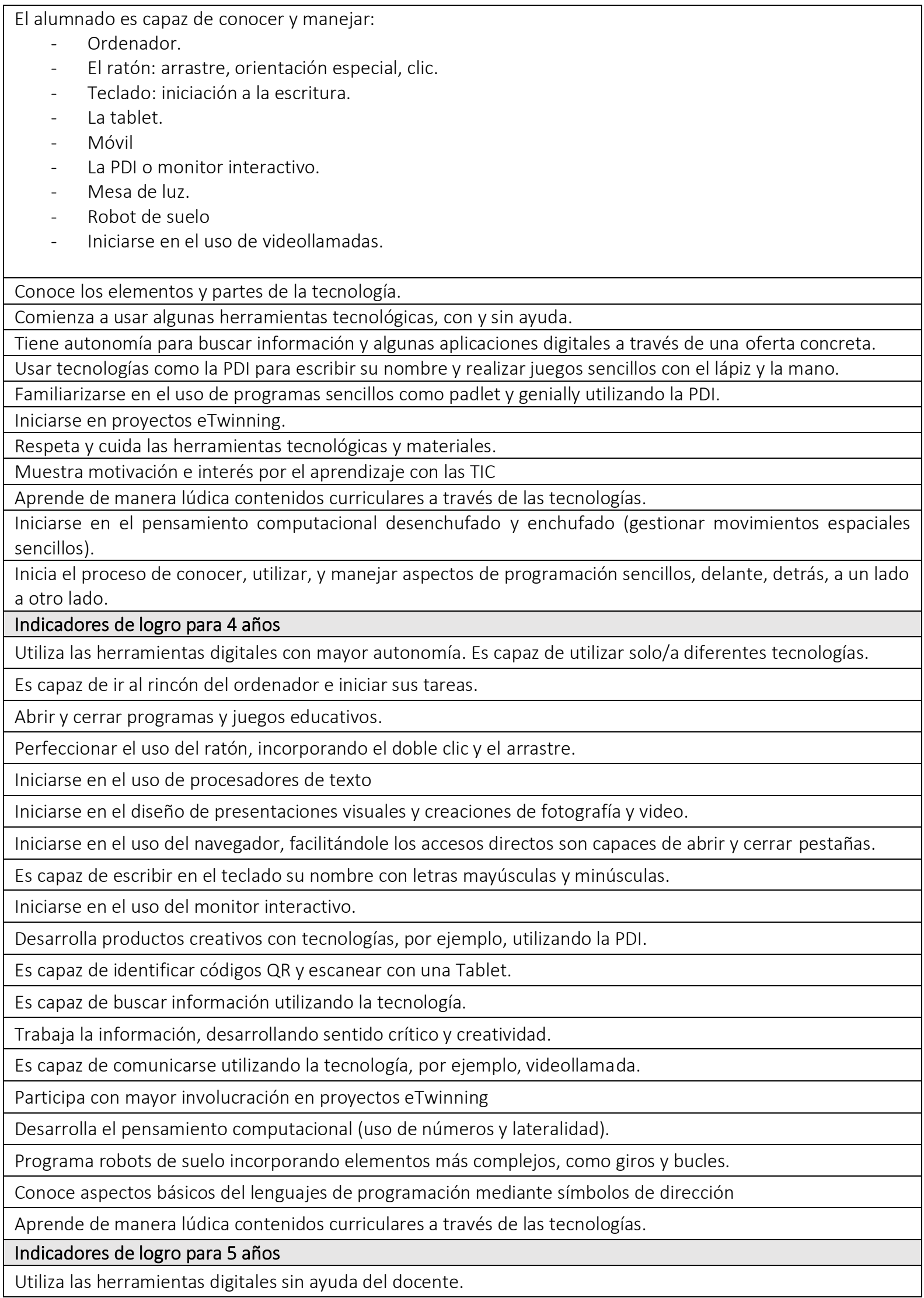




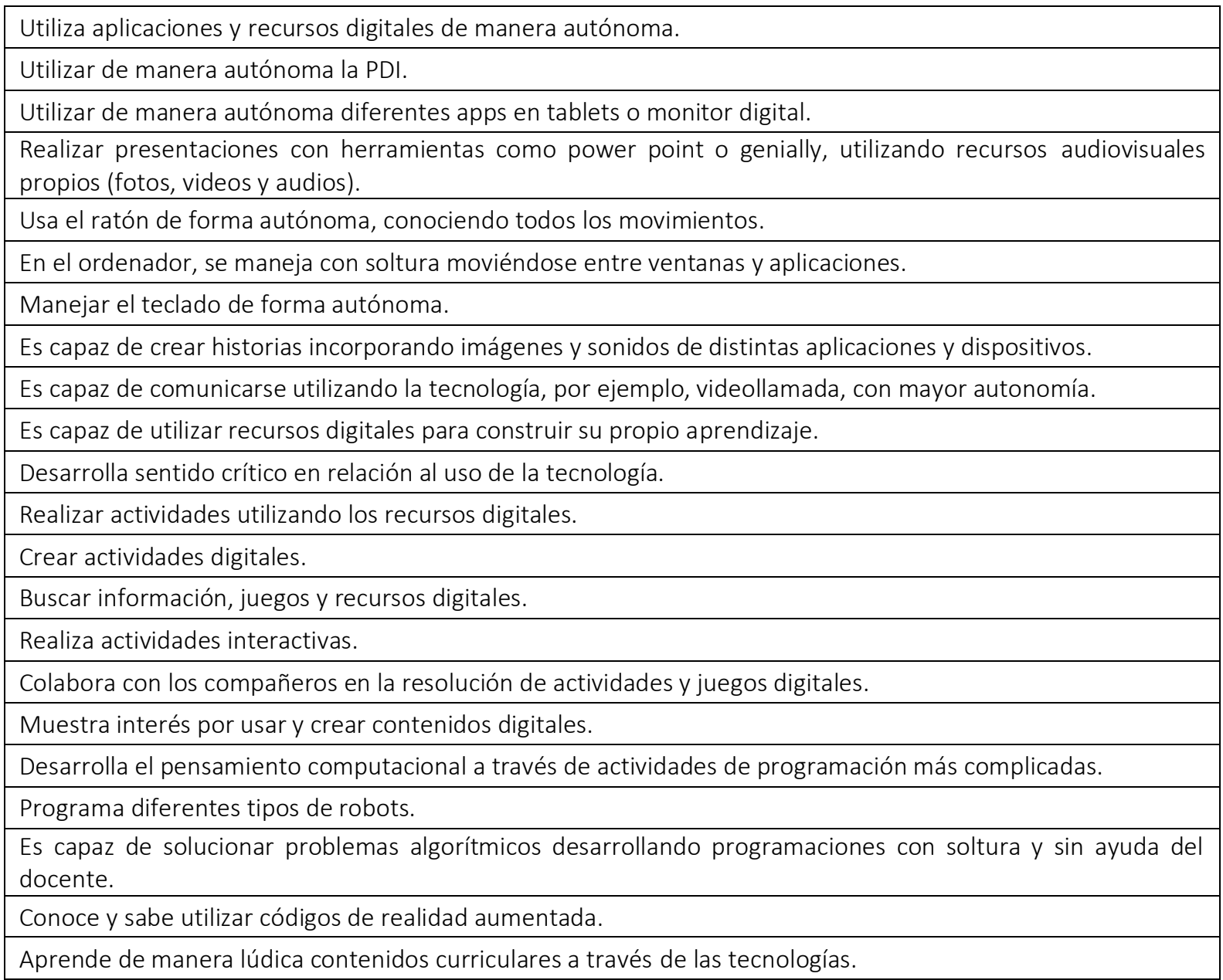

Como se puede observar, se encuentran diferentes tipos de indicadores, algunos son de aspecto técnico (usar herramientas), otros están relacionados con el tipo de aprendizaje (resolver problemas). La complejidad de las tareas y del uso de las herramientas se percibe al ir ascendiendo en los niveles. De este modo, las maestras indican para 3 años que el alumnado usa algunas herramientas con ayuda del docente, mientras que en el curso de 5 años muchas de ellas han indicado que los niños y niñas suelen tener autonomía para utilizar los recursos por sí solos.

\section{DISCUSIÓN Y CONCLUSIONES}

Este artículo realizar un primer análisis curricular en el que podemos observar que, aunque la Competencia Digital no está establecida de tal modo en la documentación existente hasta ahora en Educación Infantil, sus componentes y las consecuentes propuestas legislativas le han ido dando mayor importancia a la iniciación del alumnado en el uso adecuado de la tecnología para aprender durante esta etapa. 
En el estudio realizado con las maestras expertas en la integración de las TIC en las aulas del segundo ciclo, estas indican que varios elementos de la Competencia Digital (establecidos para Educación Primaria y Secundaria) pueden trabajarse con niños de 3-6 años, habiendo encontrado mayor acuerdo en los aspectos relacionados con el conocimiento de aplicaciones informáticas, el desarrollo de la curiosidad y motivación por las TIC, el desarrollo del pensamiento computacional, saber buscar, obtener y tratar información, y finalmente usar recursos tecnológicos para resolver problemas y comunicarse. Los aspectos relacionados con la gestión de derechos y deberes y el uso de información de manera crítica se indicaron como los que era más complicado trabajar en esta etapa. En el nivel de 5 años, algunas maestras han incorporado como propuesta de logro el inicio del sentido crítico en torno al uso de la tecnología, pero este no ha sido recogido para los niveles anteriores. Esto puede ser debido, como indican Ramírez et al (2021) en su estudio, a que la adquisición de las habilidades de forma progresiva puede ser debida al propio desarrollo madurativo del alumnado durante esos años.

Específicamente en torno la programación y la robótica encontramos que en todas las edades aparecen indicadores de logros relacionados con el desarrollo del pensamiento computacional. El 77\% de las maestras consideran que el pensamiento computacional puede trabajarse mucho o bastante en el 20 ciclo de Educación Infantil. Esto reafirma las propuestas de algunos investigadores (Bers, 2018; Ramírez, 2015). sobre la integración del pensamiento computacional antes de los 7 años. Si partimos de que aprender a programar es una alfabetización importante de este siglo, ya que nos permite comunicarnos a través de las tecnologías, no tendría sentido privar de iniciar al alumnado en estos lenguajes. Como afirma Bers (2018), la programación, al igual que sucede con la escritura, nos ayuda a comunicarnos y expresarnos de forma creativa utilizando tecnología. El estudio de García-Valcárcel y CaballeroGonzález (2019) indica que los niños de 4 años que realizan un programa propuesto de robótica mejoraron su avance en habilidades de pensamiento computacional.

Las maestras han considerado, de forma general, la formación pedagógica como un aspecto importante a la hora de integrar las TIC en el aula de infantil, lo que apoya lo encontrado en estudios anteriores, como el de Gómez-Galán, López-Meneses y Molina García (2016). Algunos estudios, como el de Magen-Nagar y Firstater (2018) indican en sus conclusiones que se debería animar a los profesores a participar formación relacionada con las TIC para que comprendan las oportunidades didácticas que ofrecen las TIC en la Educación Infantil, ya que en muchos casos, las TIC se usan como fuente para buscar información, pero no como medio para desarrollar nuevas estrategias de enseñanza. En este sentido, el trabajo de Recio (2015) indica en sus conclusiones, la necesidad de promocionar acciones formativas que se centren de manera prioritaria en el trabajo de las competencias didácticas y metodológicas de las tecnologías y no únicamente en aspectos técnicos.

Aunque la Competencia Digital se inicie de forma oficial, curricularmente hablando, en Educación Primaria, se ha podido comprobar que la presencia de la tecnología en el aula de infantil y las oportunidades didácticas que genera son de suficiente calado para valorar su desarrollo curricular de forma más específica para esta etapa en las propuestas curriculares de enseñanzas mínimas y los desarrollos curriculares autonómicos. 


\section{REFERENCIAS}

Bers, M.U. (2018). Codings as a Playground: programming and Computational Thinking in the Early Childhood Classroom. New York: Routledge.

Cabero, J. (2003). Replanteando la tecnología educativa. Revista Comunicar, 21, p. 23-30.

Chaudron, S., Di Gioia, R. y Gemo, M. (2018). Young children (0-8) and digital technology: a qualitative study across Europe. JCR Science for policy report. https://publications.jrc.ec.europa.eu/repository/handle/JRC110359

European Union (2016). DigcComp 2.0: The Digital Competence Framework for Citizens. https://publications.jrc.ec.europa.eu/repository/handle/JRC101254

European Union (2019). Key competences for lifelong learning. https://op.europa.eu/en/publication-detail/-/publication/297a33c8-a1f3-11e9-9d0101aa75ed71a1/language-en

García-Valcárcel, M. Air, Y. (2019). Robótica para desarrollar el pensamiento computacional en Educación Infantil. Revista Comunicar, 59 (27). DOI: https://doi.org/10.3916/C592019-06

Hardesen, B. y Björk, G. (2012). The digital universe of Young children. Nordic Journal of Digital Literacy, $3(7)$. https://www.idunn.no/dk/2012/03/the digital universe of young children

Hervás-Gómez, C. y Silva-Carmona, M.C. (2016). Las TIC ene I ámbito de la Educación Infantil en la provincia de Sevilla, en Gómez-Galán, K., López-Meneses, E. y Molina-García, L. (2016). Instructional strategies in teacher itraining (pp.31-36). UMET PRESS: Universidad Metropolitana, San Juan.

Magen-Nagar, N., \& Firstater, E. (2019). The Obstacles to ICT Implementation in the Kindergarten Environment: Kindergarten Teachers' Beliefs. Journal of Research in Childhood Education, 1-15. doi:10.1080/02568543.2019.1577769.

Martínez, M.C. y Gómez, M.J. (2018). Programar computadoras en Educación Infantil. EDUTEC. Revista Electrónica de Tecnología educativa, 65, 1-14. Recuperado de http://www.edutec.es/revista/index.php/edutec-e/article/view/1103/pdf

Mc Millan, J.H. y Schumacher, S. (2004). Investigación educativa. Pearson.

Orden ECD/65/2015, de 21 de enero, por la que se describen las relaciones entre las competencias, los contenidos y los criterios de evaluación de la educación primaria, la educación secundaria obligatoria y el bachillerato. https://www.boe.es/eli/es/o/2015/01/21/ecd65 
Prendes, M.P., Gutiérrez, I. y Martínez, F. (2018). Competencia digital: una necesidad del profesorado universitario en el siglo XXI. Revista de Educación a Distancia (RED), 18(56). https://revistas.um.es/red/article/view/321591

Sánchez, M.M. y Solano, I.M. (2016). Repensando el uso de metodologías en Educación Infantiil en situaciones enriquecidas con tecnologías. En Roig-Vila, R. Tecnología, innovación e investigación en los procesos de enseñanza-aprendizaje. Octaedro.

Ramírez, E., Cañedo, I. Orgaz, B., Martín, J. (2021). Evaluar competencias digitales en Educación Infantil desde las prácticas de aula. Revista pixelbit. 61, p.37-69. https://doi.org/10.12795/pixelbit.85580

Recio, S. (2015). Formación en TIC del profesorado de Educación Infantil: uso de las tecnologías y cambio metodológico. Tesis doctoral. https://digitum.um.es/digitum/handle/10201/47945

Reeves, T.C. (2000). Enhancing the worth of instructional technology research through "desing experiments" and other development research strategies. International Perspectives on Instructional Technology Research for the $21^{\text {st }}$ century.

Romero, R.; Gutiérrez-Castillo, J.J. y Puig Gutierrez, M. (2016). Libro de Actas del I Congreso internacional de Innovacióny Tecnología Educativa en Infantil (CITEl'16). Ed. Grupo de Investigación Didáctica de la Universidad de Sevilla. Sevilla. http://institucional.us.es/citei16/wp-content/uploads/2016/04/Actas_CITEl16.pdf

Romero, R., Gutiérrez-Castillo, J.J. y Puig, M. (2017). Innovación y tecnología en Educación Infantil. Editorial Universidad de Sevilla.

Sevillano, M.L. y Rodríguez, R. (2013). Integración de tecnologías de la información y la comunicación en Educación Infantil en Navarra. Pixelbit. 42, pp.75-87. https://recyt.fecyt.es/index.php/pixel/article/view/61570/37583

Zhao, Y., Pinto, A.M. y Sánchez, M.C. (2021). Digital competence in higher education research: a systematic literature review. Computers and Education, 168. https://doi.org/10.1016/j.compedu.2021.104212

\section{Para citar este artículo:}

Sánchez-Vera, M.M. (2021). El desarrollo de la Competencia digital en el alumnado de Educación Infantil. Edutec. Revista Electrónica De Tecnología Educativa, (76), 126-142. https://doi.org/10.21556/edutec.2021.76.2081 